\title{
Secondary Hyperparathyroidism, Proinflammatory Cytokines and Response to Epoietin in Anemic Maintenance Dialysis Patients
}

\author{
H. Schiffl D. Stratakis S.M. Lang \\ Section of Nephrology, Department of Internal Medicine, University Munich Innenstadt, Munich, Germany
}

Dear Sir,

There is ample evidence that excess plasma parathyroid hormone concentrations (iPTH), especially in the presence of histological ostitis fibrosa, are associated with worsening of anemia or resistance to the action of erythropoietin. This may be counteracted either by treatment with active forms of vitamin $\mathrm{D}_{3}$ or by parathyroidectomy. The mechanisms involved in the complex relationship between the autonomous parathyroid glands and erythropoiesis are not fully understood. The early response to surgery or medical therapy suggests direct effects on hematopoiesis such as suppression of endogenous erythropoietin secretion, inhibition of bone marrow erythroid progenitors or red cell survival. The continuous improvement of anemia may be further explained by decreased bone marrow fibrosis. However, data regarding the operating factors are conflicting [1]. Inflammatory cytokines such as interleukin-6 (IL-6) block erythropoiesis by their effects on the development of erythroblasts [2] and thereby anemia and responsiveness to erythropoietin. The question whether parathyroid hormone excess affects synthesis of proinflammatory cytokines remains unanswered.

We prospectively examined the effects of parathyroidectomy on IL-6 levels, hemoglobin concentrations and epoietin dose in 9 anemic patients with end-stage renal disease (5 patients on CAPD, 4 patients on hemodialysis) and severe secondary hyperparathy- roidism. There were 5 men and 4 women, aged 28-63 years, and the duration on dialysis before surgery was 38-184 months (mean 85 ). The cause of end-stage renal disease was chronic glomerulonephritis in 6 patients, chronic tubulointerstitial nephritis in 2 patients and polycystic kidney disease in 1 patient. None of the patients had absolute or relative iron deficiency, infection, inflammatory disorders, malignancy, occult gastrointestinal blood loss, aluminium toxicity or was taking drugs known to interfere with erythropoiesis. They all had normal vitamin $\mathrm{B}_{12}$ and folic acid levels, and weekly $\mathrm{Kt} / \mathrm{V}$ of at least 3.6 for hemodialysis and 2.1 for CAPD. The diagnosis of severe secondary hyperparathyroidism was made on the basis of biochemical, histological (bone biopsy), radiological and clinical parameters. Blood samples for determinations of iPTH and other chemical parameters, serum IL-6 levels, and hemoglobin concentrations were drawn prior to surgery (within 1 week) and 6 months after surgery.

Parathyroidectomy (total parathyroidectomy with a forearm transplant) resulted in each patient in a normalization of excess parathyroid hormone concentration, hypercalcemia $(2.9 \pm 0.1$ vs. $2.4 \pm 0.1 \mathrm{mmol} / \mathrm{l})$, hyperphosphatemia $(6.5 \pm 0.5$ vs. $3.4 \pm$ $0.5 \mathrm{mg} / \mathrm{dl})$ and alkaline phosphatase $(261 \pm$ 22 vs. $153 \pm 18 \mathrm{U} / \mathrm{l})$. Compared to preoperative values, the postoperative epoietin doses were significantly lower, although
Table 1. Effect of parathyroidectomy on responsiveness to epoietin therapy in 9 uremic patients

\begin{tabular}{lcc}
\hline & \multicolumn{2}{l}{ Parathyroidectomy } \\
\cline { 2 - 3 } & prior & post \\
\hline iPTH, pg/ml & $1,582 \pm 633$ & $27 \pm 9^{*}$ \\
$\mathrm{IL}-6, \mathrm{pg} / \mathrm{ml}$ & $54 \pm 18$ & $12 \pm 5^{*}$ \\
$\mathrm{CRP}, \mathrm{mg} / \mathrm{dl}$ & $1.3 \pm 0.2$ & $0.2 \pm 0.1^{*}$ \\
$\mathrm{Hb}, \mathrm{g} / \mathrm{dl}$ & $9.2 \pm 0.4$ & $10.8 \pm 0.4^{*}$ \\
EPO dose, & & \\
\multicolumn{1}{c}{$\mathrm{U} / \mathrm{kg} /$ week } & $151 \pm 35$ & $61 \pm 28^{*}$ \\
\hline
\end{tabular}

$* \mathrm{p}<0.05$ vs. preoperative values.

postoperative hemoglobin levels were significantly higher than corresponding levels before surgical therapy. Parathyroidectomy was also associated with a fall in elevated IL6 values towards values usually observed in chronic hemodialysis patients. Furthermore, successfully treated patients had significantly lower CRP values (table 1).

The worsening of anemia and the resistance to erythropoietin characterizing severe secondary hyperparathyroidism are caused not by a single pathogenetic mechanism, but may involve a number of factors operating simultaneously at different stages of the de-

\begin{tabular}{ll}
\hline KARGER & ( ) 2001 S. Karger AG, Basel \\
Fax +4161306 1234 34 -2766/01/0884-0391\$17.50/0 \\
$\begin{array}{l}\text { E-Mail karger@karger.ch } \\
\text { www.karger.com }\end{array}$ & $\begin{array}{l}\text { Accessible online at: } \\
\text { www.karger.com/journals/nef }\end{array}$
\end{tabular}

\author{
Prof. Dr. H. Schiffl \\ Med. Klinik, Klinikum der Universität München \\ Ziemssenstrasse 1 \\ D-80336 Munich (Germany) \\ Fax+49895705727, E-Mail hschiffl@medinn.med.uni-muenchen.de
}


velopment of parathyroid gland hyperplasia. The present data disclose a previously undescribed link between excess parathyroid hormone and erythropoiesis in hyperparathyroidism secondary to end-stage renal disease. Circulating IL-6 levels were found to be increased in our patients with severe secondary hyperparathyroidism as well as in 86 uremic patients with different degrees of renal osteodystrophy published by Montalban et al. [3]. The authors of the latter series found a strong correlation $(r=0.71)$ between iPTH concentrations and corresponding IL-6 levels in their 15 patients with severe secondary hyperparathyroidism (iPTH $>250 \mathrm{pg} / \mathrm{ml}$ ). Goicoechea et al. [4] described a positive correlation between IL- 6 or TNF- $\alpha$ values and erythropoietin doses in hemodialysis patients, but did not analyze the response to epoietin dose in relation to the severity of secondary hyperparathyroidism. Surgical treatment of our patients with secondary hyperparathyroidism or successful parathyroid adenomectomy of patients with primary hyperparathyroidism [5], resulted in a fall of elevated IL-6 levels into the normal range. Vitamin $\mathrm{D}_{3}$ metabolites have shown to suppress elevated IL-6 levels in diseased states [6]. Whether the beneficial effects of active vitamin $\mathrm{D}_{3}$ on anemia in patients with secondary hyperparathyroidism solely reflect the correction of excess parathyroid hormone secretion or, in addition, may also correct PTH or hypercalcemia-induced alterations in cytokine synthesis, remains to be shown.

In summary, severe secondary hyperparathyroidism represents an important factor affecting the pathogenesis of anemia in uremic patients and is considered a reversible cause of resistance to recombinant human erythropoietin therapy. The complex relationship between excess parathyroid hormone and erythropoiesis seems to involve alterations of the synthesis of proinflammatory cytokines.

\section{References}

1 Gallieni M, Corsi C, Brancaccio D: Hyperparathyroidism and anemia in renal failure. Am J Nephrol 2000;20:89-96.

2 Krantz SB: Pathogenesis and treatment of the anemia of chronic disease. Med Sci 1994;307: 353-359.

3 Montalban C, Garcia-Unzueta MT, De Francisco AL, Amado JA: Serum interleukin-6 in renal osteodystrophy: Relationship with serum PTH and bone remodeling markers. Horm Metab Res 1999;31:14-17.

4 Goicocechea M, Martin J, De Sequera P, Quiroga JA, Ortiz A, Carreno V, Caramelo C: Role of cytokines in the response to erythropoietin in hemodialysis patients. Kidney Int 1998;54: 1337-1343.

5 Grey A, Mitnick MA, Shapses S, Ellison A, Gundberg C, Insogna K: Circulating levels of interleukin-6 and tumor necrosis factor-alpha are elevated in primary hyperparathyroidism and correlate with markers of bone resorption A clinical research center study. J Clin Endocrinol Metab 1996;81:3448-3449.

6 Muller K, Bendtzen K: 1,25-Dihydroxyvita$\min D_{3}$ as a natural regulator of human immune function. J Invest Dermatol Symp Proc 1996;1:68-71. 